\title{
WIELBARK KULTUR \\ IM DOBRINER LAND 30 JAHRE SPÄTER. AKTUELLER STAND DER FORSCHUNG UND WEITERE FORSCHUNGSPERSPEKTIVEN
}

\begin{abstract}
Kurpiewski A. and Lewandowska J. 2016. Wielbark culture on the Dobrzyń Land 30 years later. Current state of research and further research perspectives. Sprawozdania Archeologiczne 68, 145-163.

The state of research on the Wielbark culure in the area of the Dobrzyń Land leaves much to be desired. Exactly thirty years ago Krystyna Hahula wrote her MA thesis titled Early Pre-Roman and Roman period in the Interfluve of Vistula, Drwęca and Skrwa rivers. A few years later the author's main findings were published in a small text called Wielbark Culture on the Dobrzyń Land. For almost three decades this work has served as a source of knowledge about settlements in the Roman period for this area. Research conducted since the beginning of the twenty-first century has shed some new light on the transformation of settlements of the region. This text does not claim to be comprehensive on the subject; it is merely an attempt to signal changes taking place in the Roman period in the Vistula, Drwęca and Skrwa interfluve in the context of the latest findings.
\end{abstract}

Key word: Dobrzyń Land, Roman period, Wielbark Culture.

Received: 10.10.2015; Revised: 21.03.2016; Accepted: 01.06.2016

Das Dobriner Land liegt am nordwestlichen Rand von Masovien, grenzt im Norden mit dem Kulmer Land und im Westen mit Kujavien. Der Stand der Forschung über WielbarkKultur in diesem Bereich lässt viel zu wünschen übrig. Genau vor dreißig Jahren, verteidigte Krystyna Hahuła am Institut für Archäologie der Nikolaus-Kopernikus-Universität

* Prosta 25/1, 87-10o Toruń, Poland; artur.kurpiewski@wp.pl

** Muzeum Ziemi dobrzyńskiej w Rypinie, Warszawska 10, 87-501 Rypin, Poland; jag.lew@wp.pl 
in Toruń, unter der Leitung von Prof. Krystyna Przewoźna-Armon die Magister-Arbeit unter dem Titel. Młodszy okres przedrzymski i rzymski w Międzyrzeczu Wisty, Drwęcy i Skrwy (Hahuła 1984). Ein paar Jahre später wurden die wichtigsten Thesen der Autorin in einem kleinen Text unter dem Titel Kultura wielbarska na ziemi dobrzyńskiej (Hahuła 1988, 87-103) veröffentlicht. Seit fast drei Jahrzehnten ist diese Arbeit ein Kompendium des Wissens über die Siedlung in der Römerzeit in diesem Gebiet.

Die Forschungen, die seit Beginn des 21. Jahrhunderts durchgeführt werden, neigen dazu, die Transformation der Besiedlung in der Region aus neuer Sicht zu betrachten. Dieser Text ist keine vollständige Studie dieser Thematik, es ist lediglich ein Versuch, die Änderungen, die in der Römerzeit in der Region zwischen Weichsel, Drewenz und Skrwa aufgetreten sind, im Lichte der neuesten Erkenntnisse zu signalisieren.

Wenn man die Siedlungssituation analysiert, kann man das Interesse in diesem Bereich in drei Hauptetappen untergliedern. Die erste Etappe beinhaltet Amateur- und Halbamateur-Forschungen aus dem 19. und dem Anfang des 20. Jhs. der Stellen in Chalin (Zieliński 1874, 86-93), Dyblin, Podlesie, Rętwiny (Zieliński 1874, 81; Brykczyński 1880, 16), Uniejewo (Hahuła 1984, 166). In der Zwischenkriegszeit untersuchte man, rettungsweise einen Friedhof in Michałkowo (Okuliczowie 1976, 444-458), und machte auch eine zufällige Entdeckung in Sadłowo (die erwähnte Stelle befindet sich nach der neuen administrativen Aufteilung auf dem Gebiet des Dorfes Nowe Sadłowo, Kr. Rypin. In der Fachliteratur ist es als Sadłowo bekannt. Administrative Grenze zwischen Nowe Sadłowo und Sadłowo verläuft entlang der nördlichen Grenze der Kiesgrube, in der sich ein Friedhof befindet (mehr dazu Kurpiewski und Lewandowska 2013, 172-173; 2015a, 358-36o).

Eine weitere Etappe der Forschung ist der sog. Zeitraum der Rettungs-Forschung. Mit diesem Termin bezeichnen die Autoren die Forschungen, die in der 6oer und 70er Jahren des 20. Jhs. geführt wurden. Es waren Arbeiten, die während eines Saisons durchgeführt wurden in den Ortschaften wie: Janowo (Kriesel 1961, 302-305; Hahuła 1993, 141-155), Jeziorki (Hahuła 1988, 91, Archiwum Muzeum w Brodnicy, weiter als: Archiwum MB), Ruże (Forschungen in Róże wurden im Jahre 1968 und 1972 während zwei Saison durchgeführt. Janikowski 1978, 163-168; Romanowska-Grabowska und Janikowski 1982, 105-138), Wojnowo (Krut 1979, 148-149), Zębowo (Janikowski 1973, 161185). Aus den Untersuchungen der. o.g Friedhöfe ist nicht die vollständige Dokumentation übrighgeblieben, in vielen Fällen wurden die Materialien vermischt, was ihre genaue Zuordung der bestimmten Teams unmöglich macht. Viele Materialien, die es schon in der Fachliteratur gibt z. B. aus der Stelle in Róże, Zębowo oder Michałkowo bedürfen einer erneuten Bearbeitung und Veröffentlichung (Kurpiewski und Lewandowska 2011, 49-50).

Die letzte Etappe, die auf den Anfang des 21. Jhs. fällt, zeichnet sich durch einen enormen Wachstum von Materialquellen im Vergleich zu den vergangenen Jahren aus. Zu nennen sind hier vor allen Dingen systematische Forschungen des Friedhofes in Kołata in den Jahren 2000-2007 unter der Leitung von Paweł Sobczyk von Muzeum Ziemi Dobrzyń- 
skiej i Kujawskiej in Włocławek. Es ist zur Zeit die einzige vollständig untersuchte Nekropole der Wielbark-Kultur im Dobriner Land, wo man 104 Bestattungen fand (Sobczyk 2004, 5-24; 2008, 201-207). Als nächstes ist der seit 2002 vom Muzeum Ziemi Dobrzyńskiej in Rypin untersuchte Friedhof in Nowe Sadłowo, auf dem man bisher 46 Gräber der Wielbark-Kultur fand.

Signifikant war auch die Zusammenarbeit und Bildung des sog. Millieus von Detektoristen, dank der viele Denkmäler aus der Römerzeit an entsprechende Institutionen übergeben wurden. So gelangen in den letzten Jahren z. B. Funde von römischen Münzen, die praktisch seit mehreren Jahrzehnten nicht registriert wurden, immer öfter an die Wissenschaftler (Romanowski 2011, 39-47; Kurpiewski und Rakoczy 2012, 161-164).

Im Vergleich zu dem Stellen-Katalog der Wielbark-Kultur im Dobriner Land, der von Krystyna Hahuła erstellt wurde, hat sich die Quellen-Datenbank stark verändert (Hahuła 1988, 87-88, 99-101). Die Anzahl der Stellen wuchs in dem für uns interessanten Gebiet auf 46, es hat sich also verdoppelt, die Anzahl der geschlossenen Gruppen wuchs über 150\% (Abb. 9, Tabelle 1, Stellenverzeichnis am Ende der Abhandlung). Verdoppelt hat sich auch die Aufstellung der numismatischen Funde (Hahuła 1988, Zeichn. 1; Romanowski 2012, 39-47, Zeichn. 8).

\section{GRÄBERFELDS}

Gräberfelds sind am stärksten vertretene Gruppe der Stellen der Wielbark-Kultur im Dobriner Land, wo man bisher 17 Nekropolen registriert hat: Ciechocin (?), Chalin, Dyblin, Janowo, Jeziorki, Kamień Kotowy, Kołat, Michałkowo, Sadłowo, Ostrowite (Es scheint, dass die Materialien aus dieser Ortschaft, die Hahula als aus dem Friedhof stammend bezeichnet (1988, 100, Zeichn. 1), man als lose Funde betrachten soll, weil wir keine Informationen über den Kontext ihrer Entdeckung haben (Malinowska 1967, 20, Taf. XIV:5), Podlesie, Rętwiny, Ruże, Uniejewo, Włocławek-Szpetal, Wojnowo, Zębowo. Natürlich sind das die Stellen mit unterschiedlichem kognitiven Wert, ein Teil davon: Ciechocin, Chalin, Dyblin, Kamień Kotowy, Podlesie, Rętwiny, Uniejewo war noch im 19. Jh. amateur-untersucht. Oft haben wir keine Informationen über die Form der Bestattung oder über ihre Ausstattung, manche Materialien wurden vermischt (z. B. Kamień Kotowy, Chalin). Leider, wie schon erwähnt, ist die Dokumentation aus meisten Stellen nicht vollständig, nicht selten existiert sie überhaupt nicht. Man soll bedenken, dass dies nicht nur für die von Amateuren im 19. Jh. ausgegrabenen Stellen gilt, sondern auch für die Untersuchungen aus den 70er Jahren des 20. Jhs.!. Die Informationen über die Nekropole in Wojnów beschränken sich auf die Chronologie der Stelle und die Anzahl der Bestattungen. Die Autoren waren nicht imstande die Materialien aus Wojnów bei keiner Institution in Włocławek, wo sie sich einst befanden, zu lokalisieren. Hingegen die einzigen Informationsquellen über den Friedhof in Jeziorka sind lose Materialien, die sich im Museum in Brodnica befinden (Hahuła 1988, 87). 
Der Quellen-Basis, den wir für die Analyse des Bestattungs-Ritusses nutzen können, beschränkt sich auf 6 Friedhöfe, auf denen man dichte, beschriebene und veröffentlichte Gruppen registriert: Janowo, Kołat (diese Stelle wurde nicht veröffentlicht, die Ergebnisse sind nur in kurzen Mitteilungen vorgestellt), Michałkowo, Nowe Sadłwo, Róże, Zębowo. Weniger hilfreich sind die Materialien aus Włocławek-Szpetal.

\section{BESTATTUNGS-RITUS}

Wir haben Daten über die Art der Bestattung aus 10 Friedhöfen, auf denen man insgesamt 270 Gräber entdeckte. Die dominierende Form der Bestattung im Dobriner Land ist das Brandgrubengrab mit 206 bisher registrierten Fällen. Einen kleinen Prozentsatz bilden die Urnengräber mit 43 Fällen. Zu Außnahmen gehören die Körpergrab, die nur an drei Stellen in Janowo, Sadłowo und Włocławek-Szpetal mit 17 Gräbern auftreten (vgl. Tab. 1). Die große Disproportion zwischen der Zahl der Urnengräber und der Brandgrubengrab ist charakteristisch für die Friedhöfe der Wielbark-Kultur auf diesem Gebiet. Die Skelettgräber treten im Dobriner Land sehr selten auf. Jeweils acht Gräber mit Bestattun-

Tabelle 1. Anteil bestimmter Sorten von Gräbern auf den Friedhöfen der Wielbark-Kultur im Dobriner Land (Zeichn. A. Kurpiewski). Die Stellennr. entsprechen den Nummern auf den Karten und im Stellenverzeichnis. Chalin - Die Einstufung der Gräber zu bestimmten Typen ist fraglich., Kamień Kotowy - 1 Grab nicht definiert. Die Autoren der Untersuchungen in Ruż unterschieden eine Gruppe von Urnen- und Brandgräbern, obwohl die Analyse der Gräber 11, 18, 24 darauf hinweist, dass wir mit Höhlen zu tun haben. Es wurde daher angenommen, dass in der Wirklichkeit mehr als 25 Gräber entdeckt wurden, worauf schon Hahuła hingewiesen hat (1984, 96-97, Archiwum MOT - Mappe Ruże). Włocławek - drei unbestimmte Gräber

\begin{tabular}{|c|c|c|c|c|c|c|}
\hline & Fundstelle & $\begin{array}{c}\text { Anzahl } \\
\text { grab }\end{array}$ & Körpergräber & Urnengräber & Brandgräber & Chronologie \\
\hline 2 & Chalin & $4 ?$ & --- & 2 & 2 & B2 \\
\hline 8 & Janowo & 21 & 8 & 6 & 7 & $\mathrm{~B} 2 / \mathrm{C} 1-\mathrm{C} 2$ \\
\hline 10 & $\begin{array}{l}\text { Kamień } \\
\text { Kotowy }\end{array}$ & 3 & ? & 2 & ? & $\mathrm{B} 2 / \mathrm{C} 1-\mathrm{Cla}$ \\
\hline 12 & Kołat & 104 & -- & $-\cdots$ & 104 & $\mathrm{~B} 2 \mathrm{a}-\mathrm{B} 2 / \mathrm{C} 1$ \\
\hline 19 & Michałkowo & 28 & 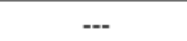 & 3 & 25 & $\mathrm{~B} 2 / \mathrm{C} 1-\mathrm{C} 2$ \\
\hline 30 & Ruże & 25 & --- & 9 & 16 & $\mathrm{~B} 2 / \mathrm{Cl}-\mathrm{Cla}$ \\
\hline 20 & $\begin{array}{l}\text { Nowe } \\
\text { Sadłowo }\end{array}$ & 46 & 8 & 5 & 33 & $\mathrm{~B} 2 / \mathrm{C} 1-\mathrm{C} 2$ \\
\hline 40 & Włocławek & $6(?)$ & 1 & 1 & 1 & $\mathrm{~B} 2 \mathrm{a}-\mathrm{C} 1 / \mathrm{C} 2$ \\
\hline 41 & Wojnowo & 13 & -- & 3 & 10 & $\mathrm{~B} 2 / \mathrm{C} 1-\mathrm{Cla}$ \\
\hline 44 & Zębowo & 20 & -- & 12 & 8 & $\mathrm{~B} 2 / \mathrm{C} 1-\mathrm{C} 1 \mathrm{a}$ \\
\hline & Razem & 270 & 17 & 43 & 206 & \\
\hline
\end{tabular}


gen wurden auf birituellen Friedhöfen in Janowo und Sadłowo sowie eins in WłocławekSzpetal (Tab. 1) entdeckt. In der Literatur werden zwei Skelett-Gräber erwähnt, die in einem der Grabhügel in Chalin gelegt wurden (Zieliński 1874, 88-89). Eine genaue Analyse des im Jahre 1874 veröffentlichen Textes führt zu Überzeugung, dass die beschriebenen Skelett-Gräber aus dieser Stelle sekundär sind und wahrscheinlich aus Mittelalter oder Neuzeit stammen (mehr dazu: Kurpiewski 2015, 271). Es wurden keine Friedhöfe entdeckt, auf denen das Skelett-Grab die einzige Form wäre.

Wenn man das Grab aus Włocławek-Szpetal nicht berücksichtigt, in dem sich Spindel mit Ohr befinden sollten und das auf die Phase B2a datiert wird (diese werden von Jarzewski bei der Besprechung der Materialien aus Szczytno erwähnt, 1938, 90), werden die übrigen Skelett-Gräber aus Janowo und Sadłowo auf die Phase B2/C1-C2 datiert (Hahuła 1993, 154; Kurpiewski und Lewandowska 2013, 187; 2015b, 81). Die nebeneinander gelegenen Friefhöfe in Janowo und Nowe Sadłowo weisen viele Ähnlichkeiten auf. Beide funktionierten in der gleichen Zeit. Sie wurden in der Phase B2/C1 gegründet, das Ende ihrer Nutzung fällt auf die Phase C2 (Hahuła 1993, 154; Kurpiewski, Lewandowska 2013, 189; 2015b, 81). Das sind die einzigen Stellen auf denen sowohl Skelett- und Urnen- sowie Brandgrubengrab auftreten. Die jüngsten Bestattungen auf beiden Friedhöfen sind die Skelett-Gräber der Kinder, in denen die Spindel A.170 gefunden wurden. In Skelett-Gräbern in Janowo wurden in zwei Fällen die Leichname der Frauen und in allen anderen der Kinder gelegt. Ähnlich sieht das in Sadłowo aus, wo in Bestattungen die Leichname der Frauen und Kinder, mitunter auch zusammen gelegt wurden. Eine anthropologische Bezeichnung besitzen 21 Gräber, die im Jahre 2012 registriert wurden. Die Bestattungen aus dem Jahre 2013 sind zur Zeit ein Gegenstand der Analyse, zweifellos waren es Kindergräber (Skelette waren $80-90 \mathrm{~cm}$ lang). Man soll auch unterstreichen, dass an beiden Stellen ein Gefäß terra sigillata entdeckt wurde (Tyszler 2012, 147-148).

Zu außergewöhnlichen Stellen im Maßstab des Dobriner Landes gehörte der Steinkreis in Ciechocin sowie die Gruppe der Graghügel in Chalin. Wenn es sich um die Stelle in Ciechocin handelt, wird an diesem Punkt das Thema der Funktion der Kreise in der Wielbark-Kultur nicht erläutert, es wurde mehrmals in der Fachliteratur beschrieben (Wołągiewicz 1976; Kokowski 1987; Walenta 1977, 1980, 1992). Über die Stelle selbst wissen wir sehr wenig, wir verfügen über keine Informationen, in welchem Teil des Dorfes der Kreis gelegt und wann genau er zerstört wurde. Von der lokalen Presse weißt man, dass es vor 1900 stattgefunden hat (Hahuła 1988, 99). In den 8oer Jahren des 20. Jhs. wurden auf dem Dorfgelände im Rahmen von AZP die Untersuchungen der Oberfläche durchgeführt, wodurch eine Stelle aus der römischen Zeit lokalisiert wurde. Sie liegt am Rande des Drewenz-Tals, nördlich von Bauten im Dorf, wir haben jedoch keine Beweise, um diese mit dem beschriebenen Steinkreis zu verbinden (Quelle AZP 39-47/32/56). An der Stelle in Chalin „untersuchte" man 6 Grabhügel mit Erdaufschüttung uns Steinumrandung. Der Friedhof befand sich auf einem kleinen Hügel, unweit des Chaliner Sees in, die Grabhügel lagen beieinander in zwei Reihen (Zieliński 1874, 86-93, mehr über Grabhügel Kurpiewski 2015, 271). 


\section{SIEDLUNGEN}

Auf dem für uns interessanten Gebiet wurden auf nur vier Siedlungsstellen irgendwelche wissenschaftliche Ausgrabungen geführt: Kołat st. 2d (nicht veröffentlichte Materialien aus Forschung von P. Sobczyk in Muzeum Ziemi Dobrzyńskiej i Kujawskiej in Włocławek), Koziróg Rzeczny st. 5 (IA 2005, 168), Łapinóż (Janosz 1952, 83, Hahuła 1988, 100), Wojnowo st. 2 (Krut 1979, 148-149). Hahuła klassifizierte noch als Siedlungen die Stellen in Pręczki (Piotrkowski 1963, 43) und Zasady-Zofijewo (Jasnosz 1952, 85), da wurden jedoch nur Untersuchungen der Oberfläche in einem kleinen Umfang durchgeführt. Viel interessantere Ergebnisse brachten die Untersuchungen der Oberfläche, die von Mitarbeitern von Museum in Brodnica in den Ortschaften: Łapinóż, Gorczenica, Gorczeniczka, Kominy durchgeführt wurden. In ihrer Folge lokalisierte man eine große Siedlungsgruppe, in denen man Spuren der metallurgischen Produktion feststellte. Mit einem großen Siedlungskomplex haben wir auch in Złotoria zu tun, wo laut AZP ein Dutzend Stellen aus der römischen Zeit entdeckt wurde (Kurpiewski und Narloch 2015, Zeichn. 1). Auf dem Dorfgelände werden oft lose Funde von Münzen und Kleidungsteilen notiert. In Muzeum Okręgowe in Torun befinden sich auch Gefäße der Wielbark-Kultur, die aus Złotoria stammen, wo sie vor mehr als 100 Jahren entdeckt wurden. Leider haben wir keine Informationen über ihre genaue Lokalisierung. Außer der Rettungs-Untersuchungen bei unterschiedlichen kleinen Aufsichtsarbeiten wurden da keine archäologischen Untersuchungen geführt, die rasche Erweiterung der Ortschaft kann zu einer vollständigen Zerstörung der archäologischen Stellen führen (Kurpiewski und Narloch 2015, 341-356).

Die größte bisher untersuchte Siedlungsfläche beträgt $325 \mathrm{~m}^{2}$, in der Ortschaft Koziróg Rzeczny, wo man 1 Feuerstelle sowie 3 Objekte mit nicht festgestellter Funktion entdeckte. Weitere fragmentarisch untersuchte Stelle (untersucht wurde lediglich $81 \mathrm{~m}^{2}$ ) ist die Siedlung Wojnowo, wo man 1 Wohnobjekt, 1 Feuerstelle, 8 Höhlen mit nicht festgestellter Funktion entdeckte. Es wurde auch das Auftreten einer Kultur-Schicht mit zahlreichem Keramik-Material festgestellt (Krut 1979, 148-149). Die Untersuchungen der Siedlung in Kołata, die neben des Friedhofs gelegen ist (st. 2a), wurden im Jahre 2013 angefangen, wo man ein Wohnobjekt registrierte (Autoren möchten sich herzlich bei Herrn Paweł Sobczyk vom Muzeum Ziemi Dobrzyńskiej i Kujawskiej in Włocławek für die Information über Untersuchungen der Siedlung an der Stelle 2d w Kołata bedanken).

\section{FUNDE VON MÜNZEN}

Münzen aus der römischen Zeit wurden in 20 Ortschaften registriert (Abb. 8, Literatur siehe: Stellenverzeichnis). Es sind zwei Schätze, entdeckt in Ortschaften: Bógpomóż -52 Hadrian-Denaren (43 Exemplera aus den Jahren 119-122 und 9, die in den Jahren 134-138 emittiert wurden) und Sitno, wo man 47 Denaren (Emission ab Hadrian, 117-138 bis 
Mark Aurel und Faustina 2., 160-167) sowie 18 lose Funde, in fünf Ortschaften fand man mehr als eine Münze: Osiek nad Wisłą, 3 Denaren: 1. Trajan 117-118 (suberatus), 2. Antoninus Pius 138-161, 3. Septimius Severus 193-194. In der gleichen Ortschaft sollten weitere 20-30 römische Münzen gefunden werden; Rumunki Głodowskie, fünf Denaren: 1. Vespesian 72-73, 2. Hadrian 125-128, 3. Antoninus Pius 138-161, 4. Lucius Verus (suberatus) 161-163, 5. Mark Aurel 161-180. Drei Münzen (Nr. 2, 4, 5) wurden von A. Dymowski als lose Funde aus Lipno (2008, 76-77) veröffentlicht. Die Autoren erreichten den Finder von Münzen und legten ihre richtige Position fest. Vielleicht kam es hier zu einer Unstimmigkeit in der Kommunikation zwischen Dymowski und dem Finder von Münzen. Der Einwohner von Lipno hat die Münzen auf dem Gelände des Dorfes Rumunki Głodowskie im Kreis Lipno entdeckt. Radziki Duże, 4 Denaren: 1. Domitian (88-89), 2. Trajan (103-111), 3. Antoninus Pius - Faustina 2. die Jüngere (vor 161); Steklin, zwei Denaren: 1. Antoninus Pius (140-143), 2. Antoninus Pius/Mark Aurel (Faustina die Ältere) 141-176, Złotoria: Sesterz von Antoninus Pius, Denar von Trajana. Aus 12 Ortschaften stammen einzelne Funde: Dobrzyń nad Wisłą, Denar von Mark Aurel (für Faustina 2. 171-176), Gorzechewo, Münze von Severen; Kujawa, Denar von Antonius Pius; Łęg-Osiek, Denar von Antonius Pius; Lukomie, Denar von Antonius Pius 138-161; Nowe Sadłowo, Fragment von Denar von Vespasian, wahrscheinlich aus dem Jahre 74, RIC II 684; Opalenica, Denar von Trajan, Orłowo, Denar von Septimus Severus; Rętwiny, Denar aus der Zeit des Keisertums; Rypin, Aureus von Decius (für Herrenia Etruscillia 249-251); Sadłowo, zwei Denaren: Faustina die Ältere und Mark Aurel; Świętosław, Denar von Mark Aurel (146-149); Teodorowo, Denar von Trajan. Insgesamt wurden im Dobriner Land 129 Münzen registriert.

\section{LOSE FUNDE}

In 11 Ortschaften wurden lose Funde (einzelne Kleidungsstücke aus Metall) entdeckt, die auf die römische Zeit datiert werden, es sind: Dobrzyń nad Wisłą (Dobrin an der Weichsel), Główina, Kobrzyniec Nowy, Rumunki Głodowskie, Sadłowo, Teodorowo, ŁęgOsiek. In den Ortschaften Radziki Duże, Wielgie, Włęcz und Złotoria wurden an einer Stelle ein paar Denkmäler aus dieser Periode gefunden. Besonders interessant scheint die im Dorf Włęcz gefundene Fibeln A.68 zu sein, die eine einzige bekannte frühere Fibeln im Dobriner Land ist. In Radziki Duże entdeckte man außer vier Münzen (früher besprochen), vier Fibeln A.124 (2 Exemplare) sowie A.127 und A.161. In der Ortschaft Wielgie unweit eines gleichnamigen Sees fand man eine Gruppe von Denkmälern, die auf die Phase B2/ C1-C1 datiert werden. Dazu gehörten die Fibeln A.39, A.95/96, A.132, A.120/124, A.162 und Fragmente mindestens zwei schlangenförmigen Armbänder aus Bronze. Die Denkmäler stammen wahrscheinlich von einem durch den Grundstückbesitzer vollständig zerstörten Friedhof (Archiwum Muzeum Ziemi Kujawskiej i Dobrzyńskiej in Włocławenk, 
weiter als MZKiD). Wie wichtig sich die Katalogisierung der losen Funde erweist, zeigen die Funde aus Dobrzyń nad Wisłą, Rumunki Głodowskie, Sadłowo oder Teodorowo, wo man Klammern entdeckte, die auf die frühe Phase der Völkerwanderung datiert werden (Abb. 7). Diese Denkmäler sind die einzigen Materialien aus Metall, die auf die Phase $\mathrm{C}_{3} /$ D datiert werden, die im Dobriner Land nur an der Stelle in Jeziorki auftraten.

\section{CHRONOLOGIE}

Die in der Ortschaft Włęcz lose gefundene Fibeln A.68, die allgemein auf die Phase B1b datiert werden (Godłowski 1985, 41) ist das älteste Denkmal der Wielbrak-Kultur, das bisher im Dobriner Land gefunden wurde. Man soll jedoch bedenken, dass die Spindeln A68, zwar sporadisch, in den Gruppen aus der Phase B2a auftreten. Im Grab 450 in Pruszcz

Tabelle 2. Die Chronologie einzelner Stellen der Wielbark-Kultur im Dobriner Land (Zeichn. A. Kurpiewski). Die Stellennr. entsprechen den Nummern auf den Karten und im Stellenverzeichnis

\begin{tabular}{|c|l|c|c|c|c|c|c|}
\hline & \multicolumn{1}{|c|}{ Fudnstellen } & B2a & B2b & B2/C1-C1a & C1 & C2 & C3/D \\
\hline 39 & Włęcz & & & & & & \\
\hline 2 & Chalin & & & & & & \\
\hline 12 & Kolat st. 2a & & & & & & \\
\hline 40 & Włocławek & & & & & & \\
\hline 17 & Lęg-Osiek & & & & & & \\
\hline 10 & Kamień Kotowy & & & & & & \\
\hline 38 & Wielgie & & & & & & \\
\hline 24 & Ostrowite & & & & & & \\
\hline 28 & Retwiny & & & & & & \\
\hline 46 & Złotoria st. 23 & & & & & & \\
\hline 27 & Radziki Duże & & & & & & \\
\hline 41 & Wojnowo & & & & & & \\
\hline 44 & Zębowo & & & & & & \\
\hline 30 & Róże & & & & & & \\
\hline 37 & Uniejewo & & & & & & \\
\hline 8 & Janowo & & & & & & \\
\hline 19 & Michałkowo & & & & & & \\
\hline 20 & Nowe Sadłowo & & & & & & \\
\hline 32 & Sadłowo & & & & & & \\
\hline 9 & Jeziorki & & & & & & \\
\hline 4 & Dobrzyń nad Wisłą & & & & & & \\
\hline 29 & Rumunki & & & & & & \\
\hline 38 & Teodorowo & & & & & & \\
\hline
\end{tabular}




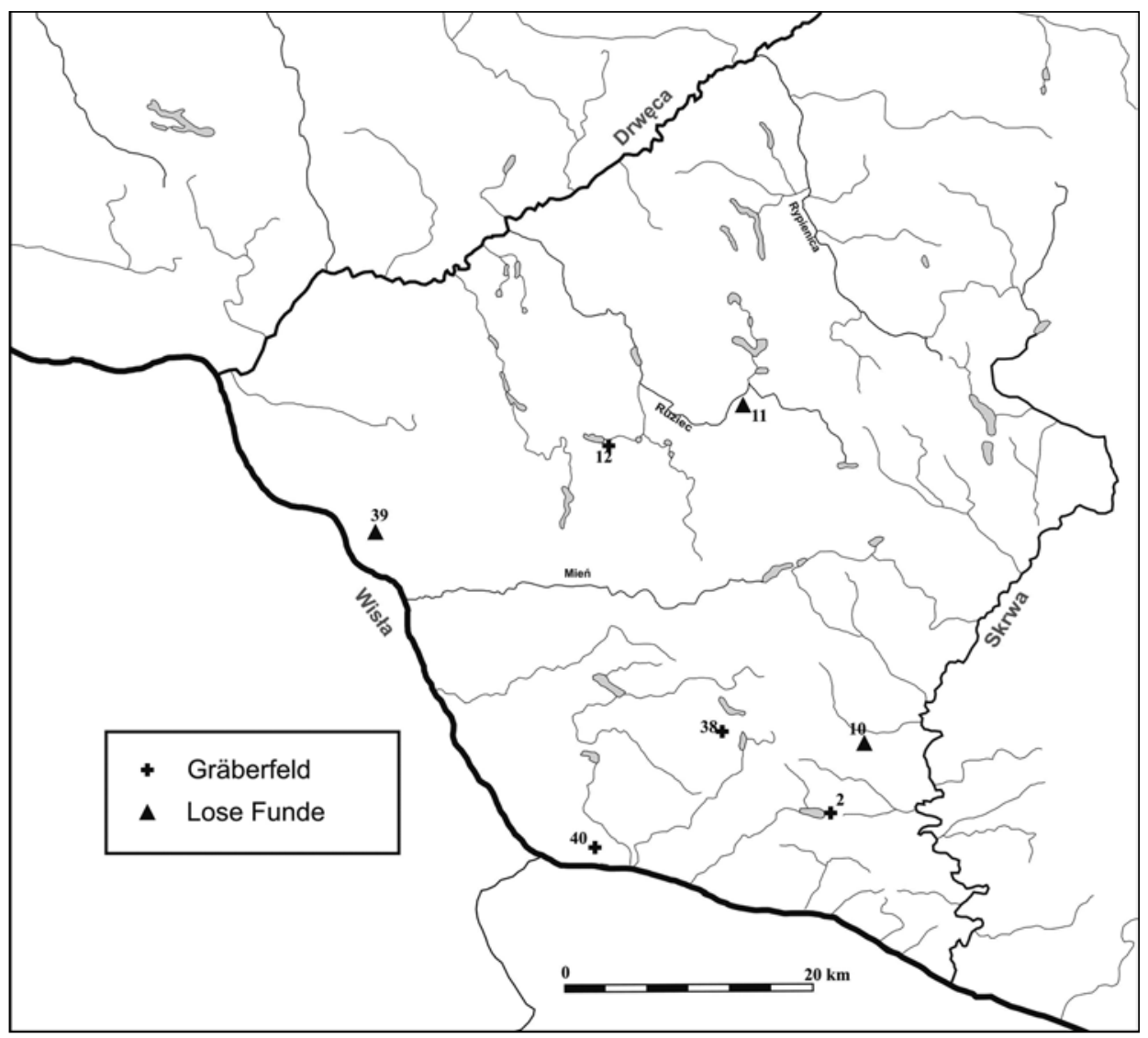

Abb. 1. Besiedlung der Wielbark-Kultur im Dobriner Land in der Phase B2, mehr dazu siehe: tabelle II (Zeichn. A. Kurpiewski)

Gdański wurde die besprochene Fibeln durch ein Paar Fibeln A.59 begleitet (Pietrzak 1997, 65, Zeichn. CXXXVII 450:2-4). Auch in Gronowo, im Grab 1, im Grabhügel 28, taucht mit der Fibel A.68 ein Paar Fibeln aus der 3. Gruppe auf - A.53 (Machajewski 2013, 32-33, Taf. XLV:28/1-1-3). Es scheint, aufgrund des heutigen Forschungsstandes, dass der Fund aus Włęcz ausgerechnet mit dieser Phase verbunden werden soll. Die ältesten Gruppen der Wielbark-Kultur im Dobriner Land, die sicher datiert werden, stammen aus der Phase B2a. Es sind Bestattungen aus Chalin, Włocławek-Szpetal, Kołata st. 2a (Sobczyk Zieliński 1878, 86-93, Hahuła 1988, 100-101, Sobczak 2011, 58-61). Es scheint, dass die ältesten Stellen der Wielbark-Kultur, die die aus dem Kulmer Land ziehende Bevölkerung gründete, südlich von Drewenz gegründet werden sollen. Die neuen Erkundungen weisen jedoch darauf hin, dass neue Siedler entlang der Weichsel gezogen sind und die Stellen aus der Phase B2a im südlichen und zentralen Teil des Dobriner Landes gelegen sind (Abb. 1). 


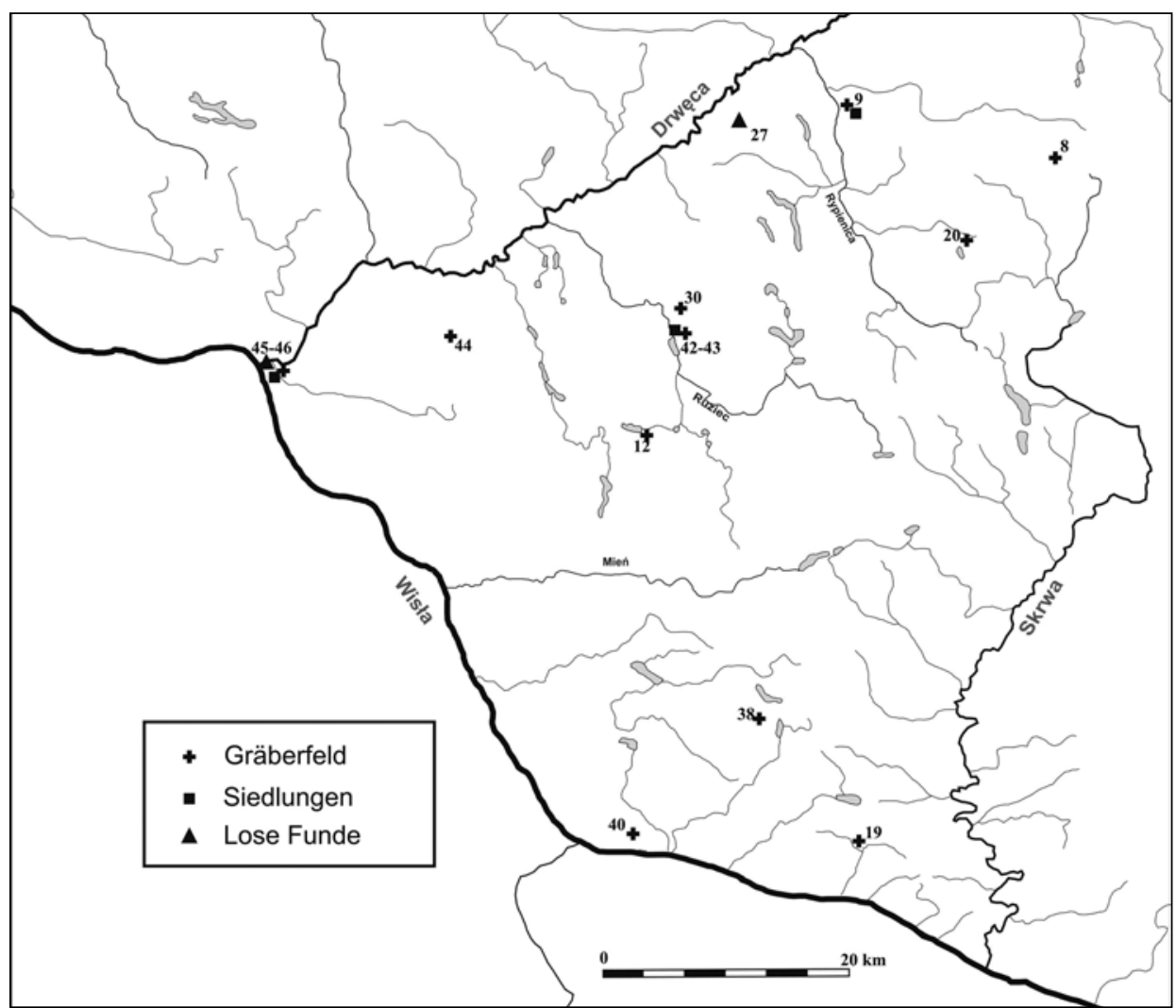

Abb. 2. Besiedlung der Wielbark-Kultur im Dobriner Land in der Phase B2/C1 und B2/C1-C2, mehr dazu siehe: tabelle II (Zeichn. A. Kurpiewski)

Die Siedlungsdichte wuchs deutlich in der Phase B2/C1 (Hahuła 1984, 107; 1988, 90), es scheint, dass erst dann das nördliche Teil der Dobriner Seenplatte, die entlang der Drewenz gelegen ist, besetzt wird. Es wurden da Friedhöfe in Janowo, Jeziorki, Nowe Sadłowo (Abb. 3), Ruż, Wojnowo und Zębowo gegründet. Im südlichen Teil beginnen die Friedhöfe in Kamień Kotowy und Michałkowo benutzt zu werden (Abb. 2). Die Stellen in Janowo, Michałkowo und Nowe Sadłowo (Abb. 4, 5) benutzte man bis Phase C2 (Okuliczowie 1976, 447-458; Hahuła 1993, 154; Kurpiewski und Lewandowska 2013, 187; 2015b, 81). Aus derselben Zeit stammt die in Włocławek-Szpetal lose gefundene Armbrust-Spindel aus der Gruppe IV mit einem rahmenförmigen Stiel (Hahuła 1988, Abb. 2:13). Die Besiedlung aus der Zeit der Völkerwanderung ist an der Stelle in Jeziorki, die seit der Phase B2/C1 funktioniert (Hahuła 1988, 90) und durch lose Funde von vier Ortschaften (Abb. 6) vertreten. Während der Untersuchungen der Oberfläche auf dem Gebiet des Dorfes Sadłowo, die von Autoren dieses Textes durchgeführt wurden, entdeckte man u.a. eine Klammer aus Bronze 

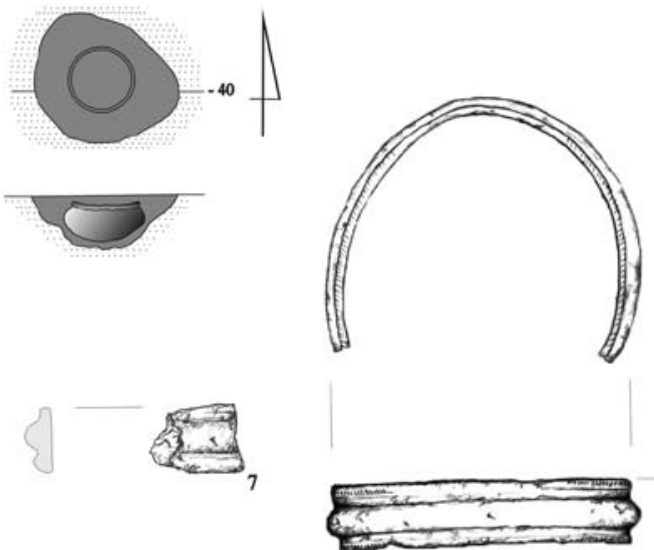

5
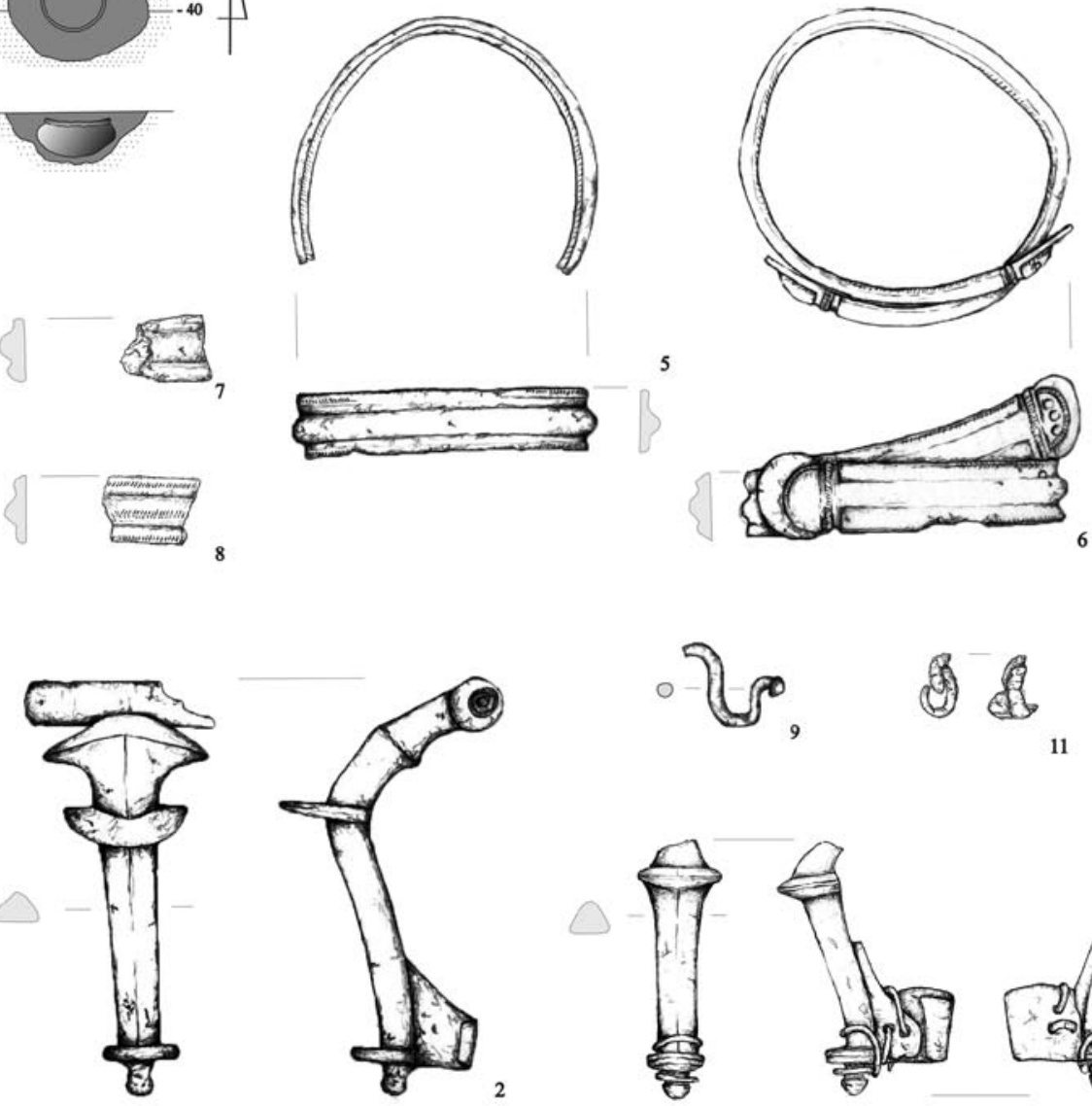

$0-10$

(1) \&
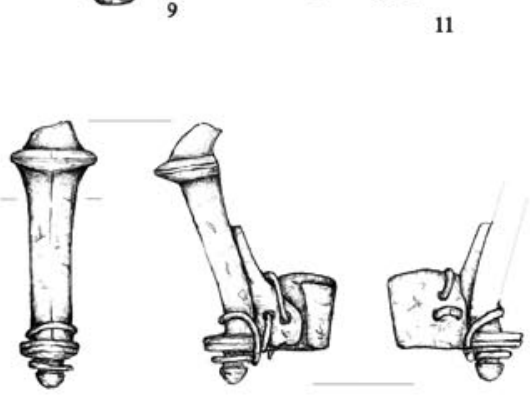

3
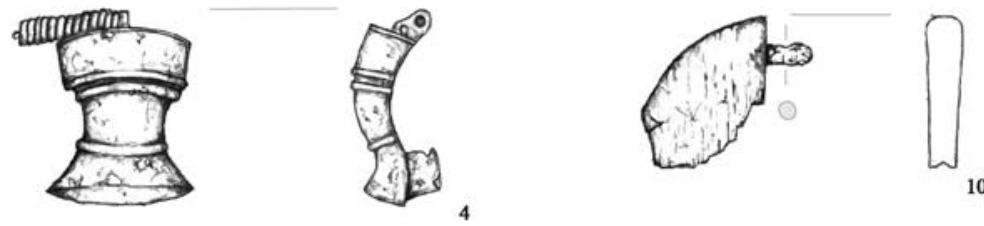

10
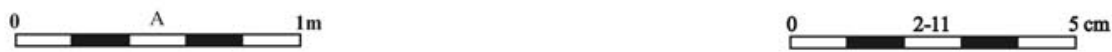

Abb. 3. Ausgewählte Grab-Gruppen aus der Phase B2/C1. Nowe Sadłowo, Kr. Rypin. A - Skala zu Grab-Plänen. Grab 29, 2-8, 11 - Bronze, 9 - Silber, 10 - Geweih, Eisen (nach A. Kurpiewski und J. Lewandowska 2015b, Abb. 5) 


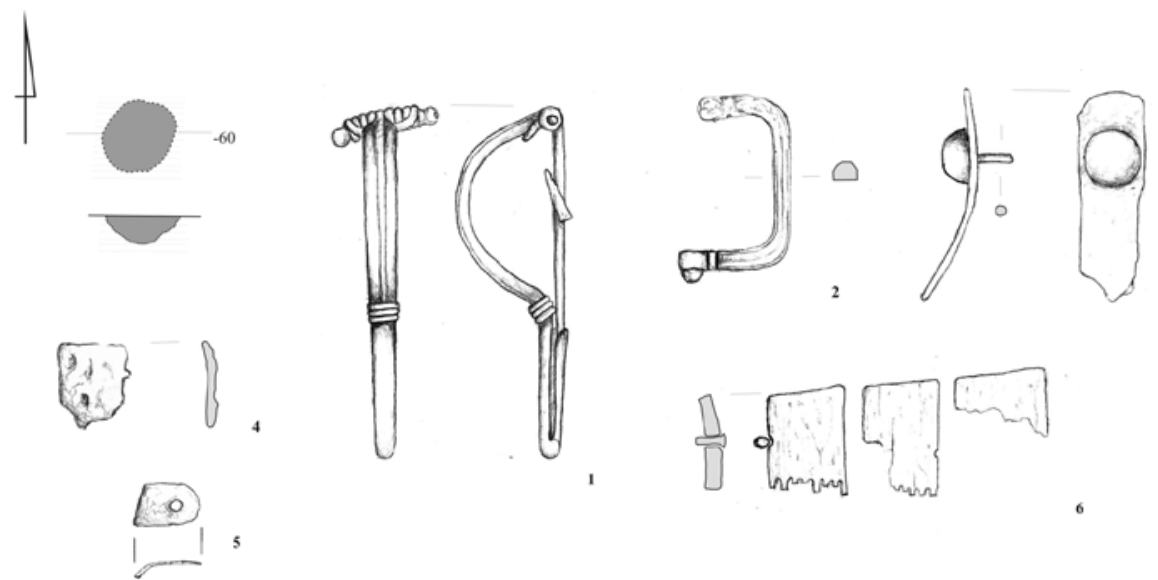

Grab 19
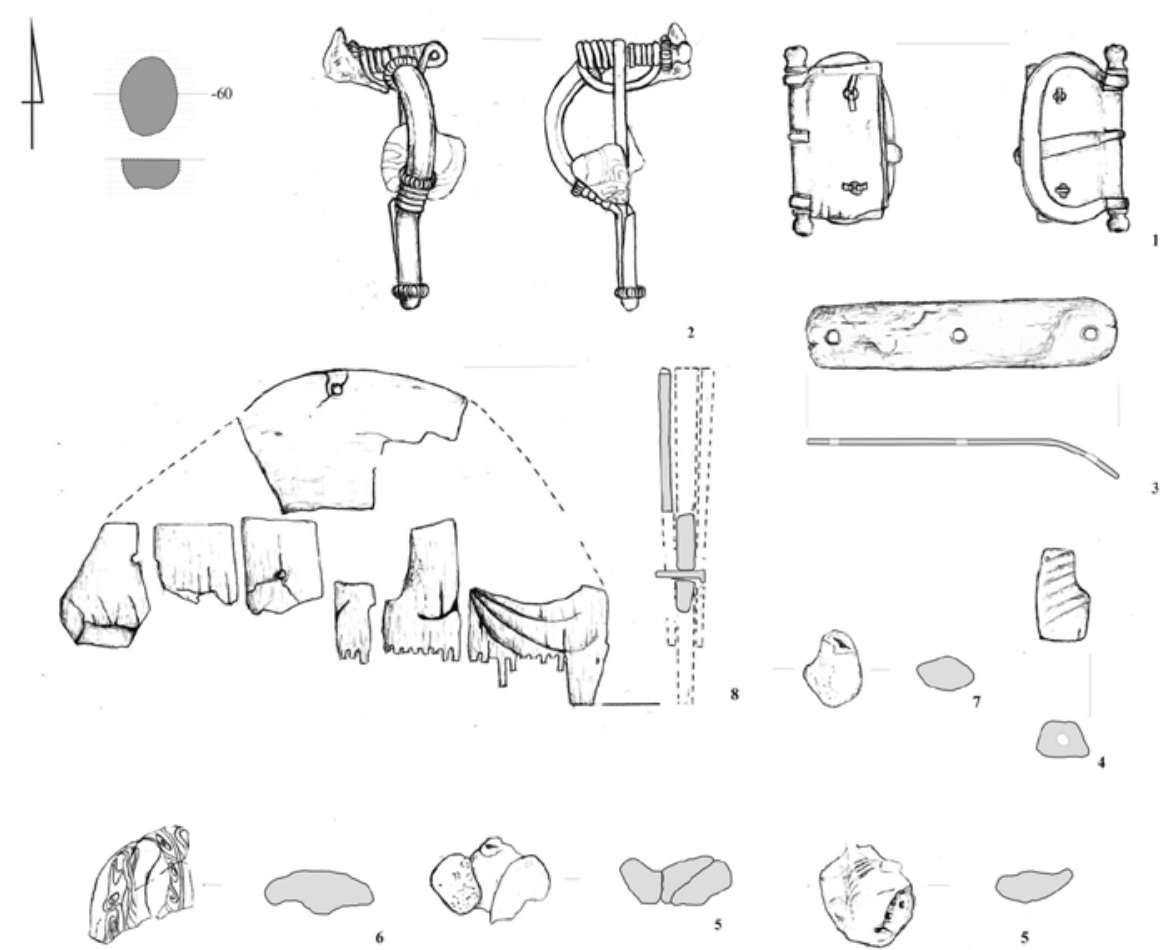

Grab 18

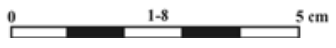

Abb. 4. Ausgewählte Grab-Gruppen aus der Phase C1-C2. Nowe Sadłowo, Kr. Rypin. Grab 18, 1, 3 Bronze, 2 Bronze, Glass, 8 Geweih, 4-7 Glass. Grab 19, 1-5 Bronze, 6 Geweih (nach A. Kurpiewski und J. Lewandowska 2013, Abb. 5) 

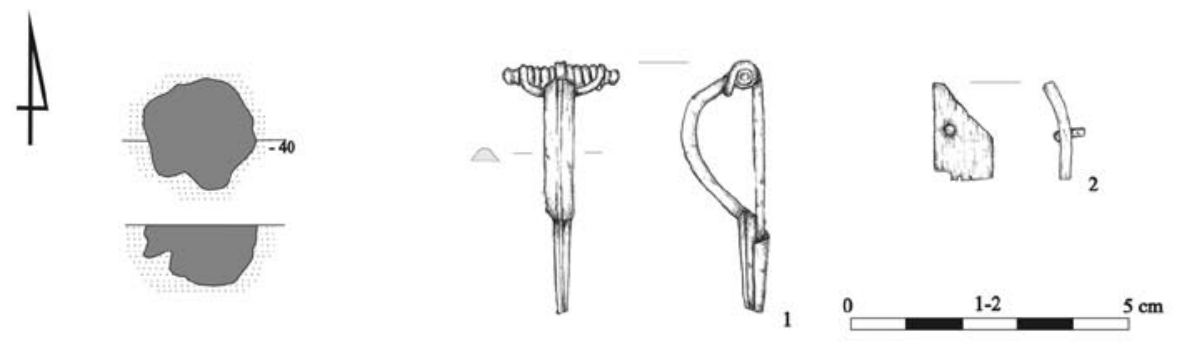

Grab 23
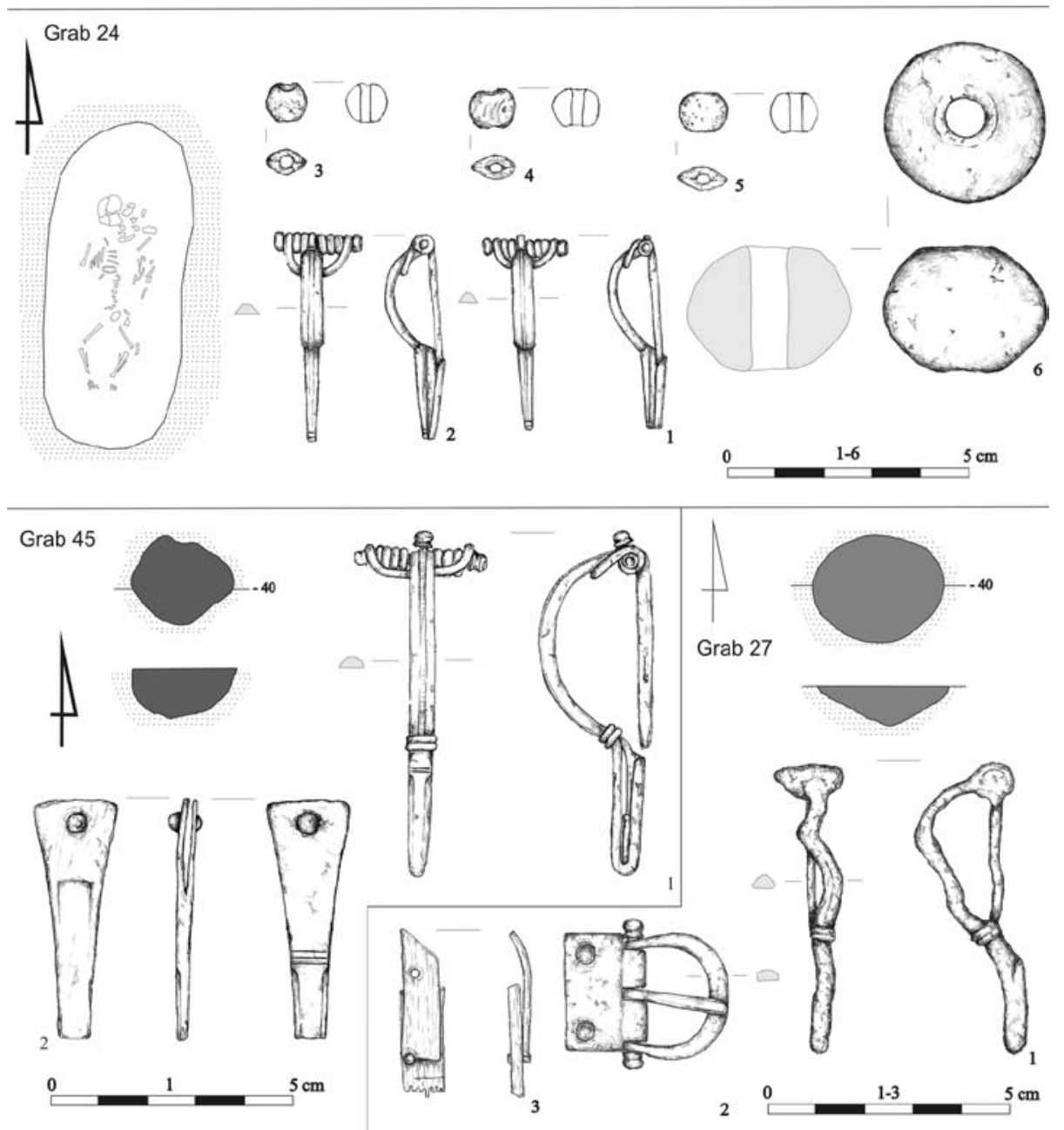

Abb. 5. Ausgewählte Grab-Gruppen aus der Phase C1-C2. Nowe Sadłowo, Kr. Rypin. Grab 23, 1 Bronze, 2 Geweih, Bronze. Grab 24, 1,2 Bronze, 3-5 Glass, 6 Lehm. Grab 27, 1, 2 Bromze, 3 Geweih. Grab 46, 1, 2 Broze (nach A. Kurpiewski und J. Lewandowska 2015b, Abb. 8) 


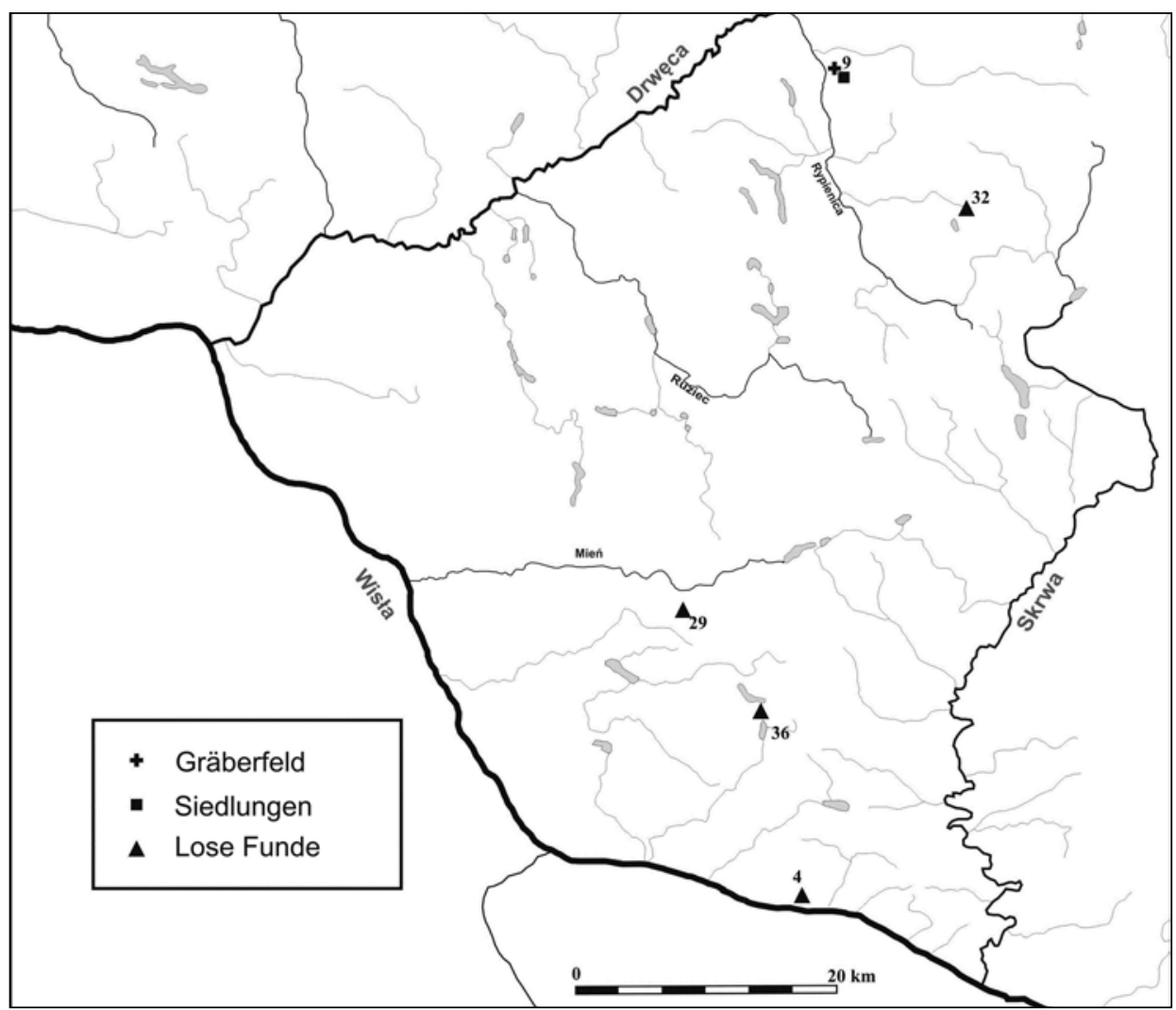

Abb. 6. Besiedlung der Wielbrak-Kultur im Dobriner Land in der Phase C3/D (Zeichn. A. Kurpiewski)

ML.H25 sowie eine Fibeln des Typs Gródek 47 (Abb. 7:2-3). Die Stelle liegt ca 600 Meter nord-östlich vom Friedhof in Nowe Sadłowo, der von Autoren untersucht wurde. In der Ortschaft Rumunki Głodowskie registrierte man eine Schnallen, die den Typ ML.H46 ähnelt (Abb. 7:1). Darüber hinaus fand man eine Schnallen, die auf diese Periode datiert wird, in Dobrin an der Weichsel (Romanowski 2011, 44), dagegen in Teodorowo endeckte man eine Schnallen des Typs ML.H17 (Abb. 7:4, nicht veröffentlichte Materialien aus der Sammlung von Muzeum Ziemi Kujawskiej i Dobrzyńskiej we Włocławku).

\section{ZUSAMMENFASSUNG}

Das Bild der Besiedlung der Wielbark-Kultur im Dobriner Land, das in diesem Text vorgestellt wird, ist wohl weit von der Wirklichkeit. Das Zwischenstromland von Weichsel, Drewenz und Skrwa war durch Generationen von Archäologen übersehen, unglücklich er- 

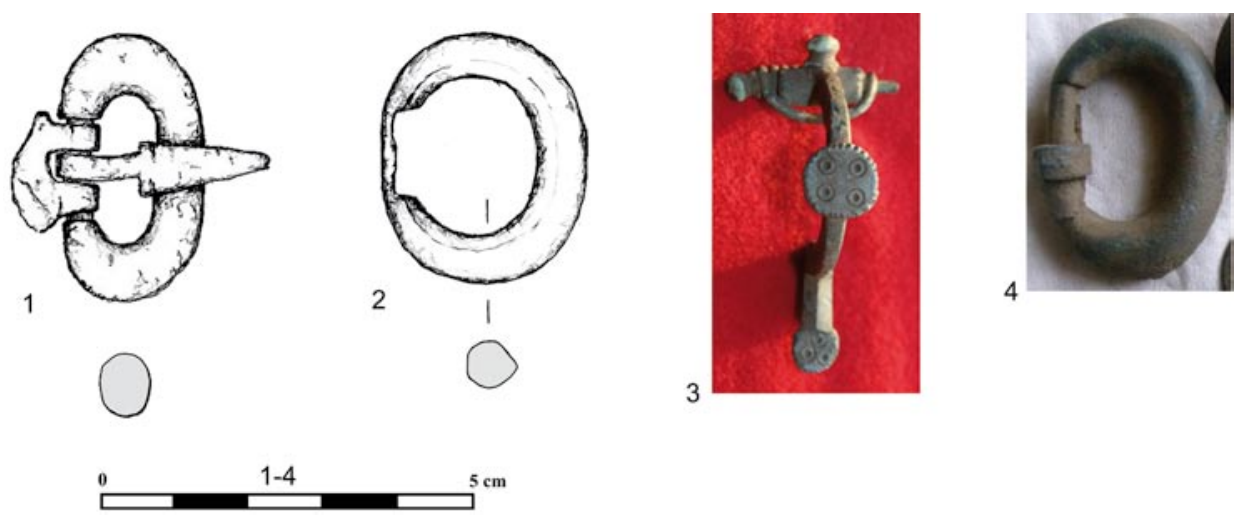

Abb. 7. Ausgewählte Funde aus der Phase C3/D. 1- Rumunki Głodowskie, Kr. Lipno; 2, 3 - Sadłowo, Kr. Rypin; 4 - Teodorowo, Kr. Lipno, 1-2 M. Olszewska, foto 3. J. Lewandowska; foto 4. A. Kurpiewski (alles lose Funde, Bronze)

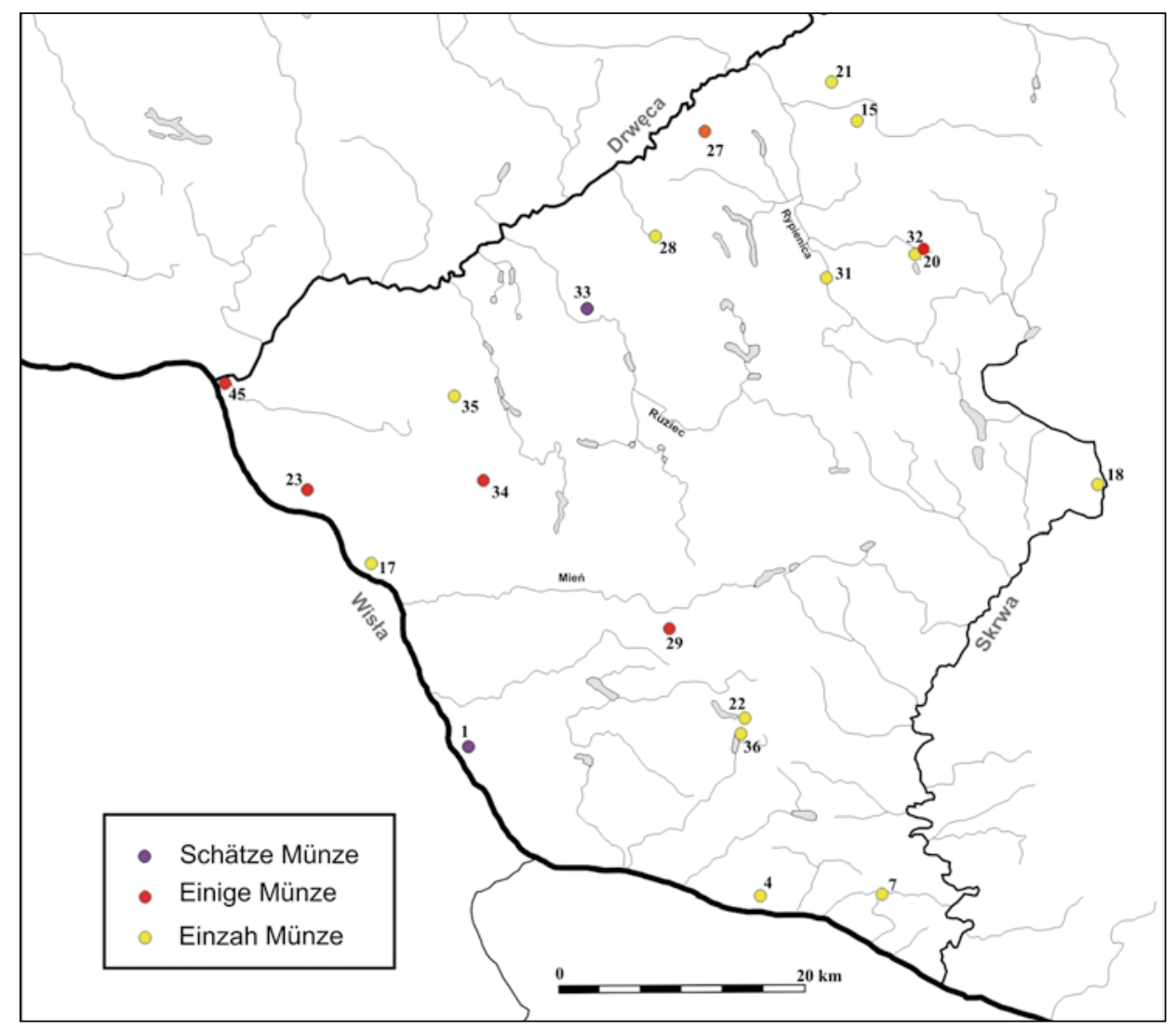

Abb. 8. Funde der römischen Münzen im Dobriner Land (Zeichn. A. Kurpiewski) 


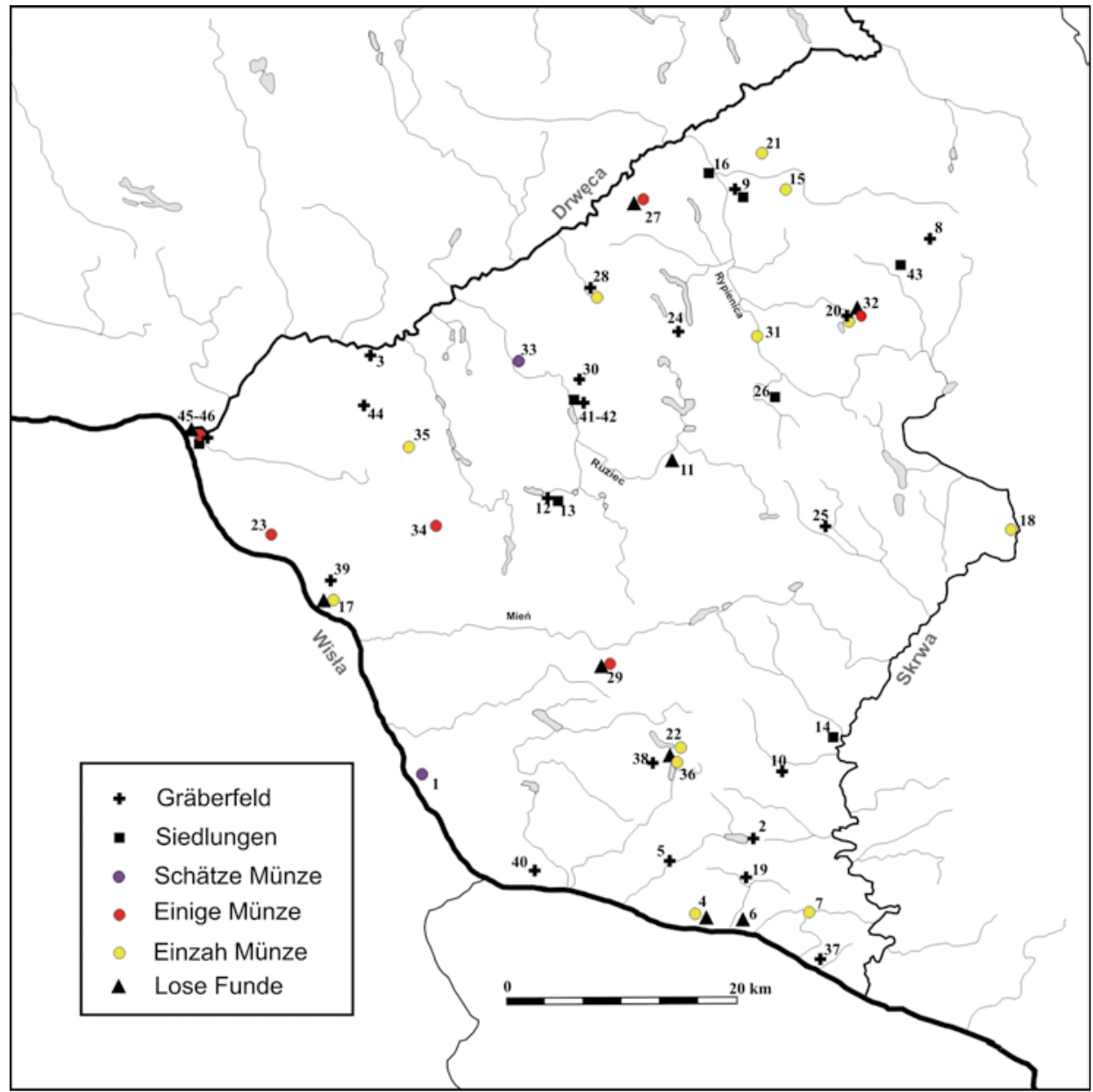

Abb. 9. Besiedlung der Wielbrak-Kultur im Dobriner Land in der römischen Zeit (Zeichn. A. Kurpiewski) 
forscht und veröffentlicht. Man soll bedenken, dass es ein unheimlich interessantes Gebiet ist unter anderen bei Überlegungen zum Thema der Bewegung der Wielbark-Kultur zum Anfang der späten römischen Periode. Wie schon früher erwähnt wurde, sollte man noch mal das Material aus dem besprochenen Gebiet aus den Forschungen im 20. Jhs. bearbeiten. Man soll unterstreichen, dass im Dobriner Land, laut der AZP-Untersuchungen, mehr als 200 Stellen lokalisiert sind, die auf die römische Zeit datiert werden. Sie bedürfen einer neuen Verifizierung. Schlüsselfunktion scheint die Veröffentlichung der Forschungsergebnisse vom Friedhof in Kołata sowie die Fortsetzung der im Jahre 2013 begonnenen Untersuchungen der Siedlung zu haben. Die Priorität für die Autoren ist die vollständige Untersuchung des Friedhofs in Nowe Sadłowo sowie die Erkundung der äußerst vielversprechenden Stelle in Sadłowo (Kurpiewski und Lewandowska 2013, 172-190; 2015a, 357372; 2015b, 79-89, wird gedruckt).

\section{Stellenverzeichnis der Wielbark-Kultur im Dobriner Land (Abb. 9)}

Das Stellenverzeichnis mit einer Karte, die die Besiedlung in der römischen Zeit im Dobriner Land darstellt, wurde schon an einer anderen Stelle veröffentlicht (Kurpiewski und Lewandowska 2015a, 365, Abb. 3).Für einen besseren Überblick entschied man sich, das Verzeichnis auch in diesem Text zur Verfügung zu stellen.

1. Bógpomóż - Kr. Lipno, Zieliński 1905, 352; Kubiak 1979, 25; Romanowski 2008, 16; 2. Chalin - Kr. Lipno, Zieliński 1874, 86-93; A. Kurpiewski 2015, 271, 3. Ciechocin - Kr. Golub-Dobrzyń, K. Hahuła 1988, 99; 4. Dobrzyń nad Wisłą - Kr. Lipno, Romanowski 2008, 2012, 44; 5. Dyblin - Kr. Lipno, Brykczyński 1880, 14; Zieliński 1874, 81; Hahuła 1984, 131, 1988, 99; 6. Główina - Kr. Płock, Kempisty 1965, 25; Cegłowski et alia 2010, 91; 7. Gorzechewo - Kr. Płock, Romanowski 2008, 28; 8. Janowo - Kr. Brodnica, Kriesel 1961, 302-305; Hahuła 1993, 141-155; Tyszler 1999, 58-65; 9. Jeziorki - Kr. Brodnica, Archiwum Muzeum w Brodnicy, Hahuła 1988, 91, ryc. 3-4; 10. Kamień Kotowy - Kr. Lipno, Echa 1900, R. III, nr 56, 1-2; Kempisty 1965, 25; Hahuła 1988, 99, ryc. 2, 3; Cegłowski et alia 2010, 91; 11. Kobrzyniec Nowy - Kr. . Rypin, Zielonka 1967, 59; 12. Kołat st. 2a - Kr. Lipno, P. Sobczyk 2004; 2008, 204, 2011, 58-61; 13. Kołat st. 2d, nicht veröffentlichte Materialien MZDiK, 14. Koziróg Rzeczny st. 5 - Kr. Lipno, Informator Archeologiczny 2005, 168; 15. Kujawa - Kr. Brodnica, Lissauer 1887, 148; Romanowski 2008, 55; 16. Lapinóż - Kr. Brodnica, Janosz 1952, 83; Hahuła 1988, 100; 17. Łęg-Osiek - Kr. Toruń, nicht veröffentlichte Materialien, Archiwum Wojewódzkiego Konserwatora Zabytków w Toruniu; 18. Łukomie - Kr. Sierpc, Dymowski 2008, 78; Romanowski 2008, 72; 19. Michałkowo - Kr. Lipno, Jakimowicz 1935, 226; Okuliczowie 1976, 447-458; 2o. Nowe Sadłowo, Kr. Rypin, Antoniewicz 1930, 313; Jasnosz 1952, 85-86; Łęga 1956, 25, 30; Hahuła, 1988, 100; Stawiarska 1999, 225; Tyszler 1999, 41-42, 139; Andrzejowski 2003, 33-45; Kurpiewski und Lewandowska 2013, 172-190; 2015a, 357-372; 2015b, 79-89; 21. Opalenica - Kr. Brodnica, W. Schwantd 1905, s. 140; S. Bolin 1926, s. 103; 22. Orłowo - Kr. Lipno, nicht veröffentlichte Materialien MZKiD; 23. Osiek - Kr. Toruń, Dymowski 2008, 82, 2011, 166; Romanowski 2008, 94-95; 
24. Ostrowite - Kr. Rypin, Malinowska 1967, 20; Hahuła 1988, 100; 25. Podlesie - Kr. Sierpc, Brykczyński 1880, 16; Kempisty 1965, 49-50; Hahuła 1988, 100; 26. Pręczki - Kr. Rypin, Piotrowski 1963, 43; 27. Radziki Duże - Kr. Rypin, Kurpiewski und Lewandowska 2011, 49-56; Kurpiewski und Rakoczy 2012, 161-164; 28. Rętwiny - Kr. GolubDobrzyń, Brykczyński 1880, 16; Hahuła 1988, 97, 100; Romanowski 2008, 112; 29. Rumunki Głodowskie - Kr. Lipno, nicht veröffentlichte Materialien MZDR; Dymowski 2008, 76-77, 2011, 159; Romanowski 2008, 59; 30. Ruże - Kr. Golub-Dobrzyń, RomanowskaGrabowska, Janikowski 1982, 105-138; 31. Rypin - Kr. Loco, Kubiak 1979, 67; Romanowski 2008, 113; 32. Sadłowo - pow. Rypin, nicht veröffentlichte Materialien MZDR; 33. Sitno - Kr. Golub-Dobrzyń, Zieliński 1900, 141, 1905, 351-352; Kunisz 1973, 103-104; Romanowski 2008, 121; 34. Steklin - Kr. Toruń, Romanowski 2008, 129; Dymowski 2011, 179; 35. Świętosław - Kr. Golub-Dobrzyń, Kubiak 1979, 71; Romanowski 2008, 133; 36. Teodorowo - Kr. Lipno, nicht veröffentlichte Materialien MZKiD; 37. Uniejewo - Kr. Płock, G. Zieliński 1900, s. 141; K. Hahuła 1988, s. 100, 38. Wielgie - Kr. Lipno, nicht veröffentlichte Materialien MZKiD, 39. Włęcz - pow. Toruń, Archiwum WKZT, 4o. Włocławek-Szpetal - Kr. Loco, Madajski 1937, 76-79; Jażdżewski 1938, 90; Hahuła 1988, 100-101; 41. Wojnowo st. 1 - Golub-Dobrzyń, Krut 1979, 148-149; 42. Wojnowo st.2 - Kr. Golub-Dobrzyń, Krut 1979, 148-149; 43. Zasady - Kr. Rypin, Jasnosz 1952, 85; 44. Zębowo - Kr. Toruń, Janikowski 1973, 161-185; 1978b, 149-155; 45. Złotoria Kr. Toruń, Schwantd 1905, 140; Bolin 1926, 103; Schindler 1940, 50; Kubiak 1979, 79; Wołągiewicz 1993, 30, 86, 105; Kurpiewski und Narloch 2015, 349. 46. Złotoria st. 23 Kr. Toruń, Kurpiewski und Narloch 2015, 341-355.

\section{Literatur}

Andrzejowski J. 2003. „Jakieś wazy szklanki” czyli o importach rzymskich z Sadłowa. In A. Bursche und R. Ciołek (Hrsg.), Antyk i Barbarzyńcy. Księga dedykowana Profesorowi Jerzemu Kolendo $w$ siedemdziesiąta rocznice urodzin. Warszawa: Instytut Archeologii UW, 33-45.

Antoniewicz W. 1930. Terra sigillata znaleziona w Sadłowie, pow. Rypiński. In Księga pamiątkowa ku czci 7o-lecia urodzin prof. dr Wt. Demetrykiewicza (= Bibljoteka Prehistoryczna 1). Poznań: Polskie Towarzystwo Prehistoryczne, 311-317.

Bolin S. 1926. Die Funde römischer und byzantinischer Münzen in Ostpreussen. Prussia 26, 203240.

Brykczyński A. 1880. Sprawozdanie z poszukiwań archeologicznych w 1878 roku. Zbiór wiadomości do antropologii krajowej 4, 16.

Cegłowski, S., Demkowicz, K., Janiak R. und Łuczak P. 2010. Skarby z ziemi wydobyte. Płock: Muzeum Diecezjalne w Płocku.

Dymowski A.2008. Najnowsze znaleziska monet rzymskich z prawobrzeżnego Mazowsza i Podlasia. Wiadomości Numizmatyczne 52, 70-98. 
Godłowski K. 1985. Przemiany kulturowe i osadnicze w południowej i środkowej Polsce w młodszym okresie przedrzymskim i $w$ okresie rzymskim (= Prace Komisji Archeologicznej PAN, Oddziat Kraków 23). Kraków: Ossolineum.

Hahuła K. 1984. Młodszy okres przedrzymski i rzymski w Międzyrzeczu Wisty, Drwęcy i Skrwy. Toruń (unpublizierte Magisterarbeit im Archiv des Archäologisches Instituts, Nicolaus Copernicus Universität in Toruń).

Hahuła K. 1988. Kultura wielbarska na Ziemi Dobrzyńskiej. In J. Gurba und A. Kokowski (Hrsg.), Kultura wielbarska $w$ młodszym okresie rzymskim 1. Lublin: Wydawnictwo UMCS, 87-103.

Hahuła K. 1993. Cmentarzysko kultury wielbarskiej w Janowie, woj. Toruńskie. Wiadomości Archeologiczne 52(2), 141-155.

Informator Archeologiczny. 2005. Bógpomóż, 94.

Informator Archeologiczny. 2005. Koziróg Rzeczny, 68.

Jakimowicz R. 1935. Sprawozdanie z działalności Państwowego Muzeum Archeologicznego za 1927 rok. Wiadomości Archeologiczne 13, 213-278.

Janikowski J. 1973. Wyniki badań na cmentarzysku ciałopalnym kultury wenedzkiej w Zębowie, pow. Toruń. Rocznik Muzeum w Toruniu 5, 161-185.

Janikowski J. 1978a. Badania ratownicze na cmentarzysku z okresu wpływów rzymskich w Ruży, pow. Golub-Dobrzyń, w 1971 r. In Komunikaty Archeologiczne Badania wykopaliskowe na terenie województwa bydgoskiego w latach 1970-1972. Bydgoszcz: Wojewódzki Konserwator Zabytków w Bydgoszczy, 163- 168.

Janikowski J. 1978b. Badania ratownicze na cmentarzysku z okresu wpływów rzymskich w Zębowie, pow. Toruń. In Komunikaty Archeologiczne Badania wykopaliskowe na terenie województwa bydgoskiego w latach 1970-1972. Bydgoszcz: Wojewódzki Konserwator Zabytków w Bydgoszczy, 149- 155.

Jaskanis J. 1976. Kurhany typu rostołckiego (z badań nad kultura wschodniopomorsko-mazowiecka z późnego podokresu rzymskiego we wschodniej Polsce). In K. Godłowski (Hrsg.), Kultury archeologiczne i strefy kulturowe $w$ Europie Środkowej $w$ okresie wplywów rzymskich (= Zeszyty Naukowe Uniwersytetu Jagiellońskiego 22). Warszawa-Kraków: Instytut Archeologii Uniwersytetu Jagielońskiego, 215-252.

Jasnosz S. 1952. Badania powierzchniowe nad Rypiennicą i Pissą. Sprawozdania Państwowego Muzeum Archeologicznego $w$ Warszawie 4 (3-4), 85-86.

Jażdżewski K. 1938. Gocki grób z połowy II wieku i grób popielnicowy z IV wieku po Ch. w Szczytnie w pow. Włocławskim. Z Otchlani Wieków 13, 77-94.

Kempisty A. 1965. Obrządek pogrzebowy w okresie rzymskim na Mazowszu. Światowit 26, 5-163.

Kriesel G. 1961. Prace wykopaliskowe Zakładu Antropologii UMK w Janowie, pow. Rypin. Przegląd Archeologiczny 27, 302-305.

Kubiak S. 1979. Znaleziska monet rzymskich na Mazowszu i Podlasiu. Warszawa: Ossolineum.

Kunisz A. 1973. Katalog skarbów monet rzymskich odkrytych na ziemiach polskich (= Materiaty do prahistorii ziem polskich 5. Epoka Żelaza). Warszawa: Instytut Historii Kultury Materialnej PAN. 
Kurpiewski A. 2015. Wielbark culture barrow in Wojsze near Ostrołęka in comparison with other objects of this type on the right-bank Mazovia and Podlasie region. Sprawozdania Archeologiczne 66, 259-276.

Kurpiewski A. und Lewandowska J. 2011. „Luźne” znaleziska z okresu rzymskiego z okolic Radzik Dużych, gm. Wąpielsk, pow. Rypin, woj. kujawsko - pomorskie. Nowe materiały do poznania kultury wielbarskiej na ziemi dobrzyńskiej. Rocznik Muzeum Ziemi Dobrzyńskiej w Rypinie 2, 49-56.

Kurpiewski A. und Lewandowska J. 2013. Sadłowo - nowa karta w badaniach osadnictwa kultury wielbarskiej na ziemi dobrzyńskiej. Wiadomości Archeologiczne 64, 172-190.

Kurpiewski A. und Lewandowska J. 2015a. „Stare” cmentarzysko odkryte na nowo. O Sadłowie raz jeszcze. Pomorania Antiqua 24, 357-372.

Kurpiewski A. und Lewandowska J. 2015b. Cmentarzysko kultury wielbarskiej w miejscowości Nowe Sadłowo, gm. Rypin, woj. kujawsko-pomorskie w świetle najnowszych badań archeologicznych. In A. Janowski, K. Kowalski, B. Rogalski und S. Słowiński (Hrsg.), XIX Sesja Pomorzoznawcza ( = Acta Archaeologica Pomoranica 5). Szczecin: Stowarzyszenie naukowe archeologów polskich oddział w Szczecinie, Muzeum Narodowe w Szczecinie, Muzeum Archeologiczno-Historyczne w Stargardzie, 79-89.

Kurpiewski A. und Lewandowska J. im Druck. Cmentarzysko kultury wielbarskiej w Sadłowie, pow. Rypin w świetle badań w latach 2011-2012. Rocznik Muzeum Ziemi Dobrzyńskiej w Rypinie 3.

Kurpiewski A. und Narloch K. 2015. Zagadkowy obiekt kultury wielbarskiej w Złotorii koło Torunia. Pomorania Antiqua 24, 341-356.

Kurpiewski A. und Rakoczy J. 2013. Znaleziska rzymskich denarów z Radzik Dużych, gm. Wąpielsk, pow. Rypin. Biuletyn Numizmatyczny 3(371), 161-164.

Krut O. 1979. Wojnowo, woj. Włocławek. Informator Archeologiczny (badania rok 1978), 149.

Lissauer A. 1887. Die prähistorischen Denkmäler der Provinz Westpreussen und der angrenzenden Gebiet. Leipzig: Commissions-Verl. von Wilhelm Engelmann.

Łęga W. 1956. Handel między państwem rzymskim a Pomorzem nadwiślańskim od I w. przed n.e. do VI w. n.e. Przegląd Archeologiczny 10, 5-85.

Machajewski H. 2013. Gronowo. Ein Gräberfeld der Wielbark-Kultur in Westpommern (= Monumenta Archaeologica Barbarica 18). Warszawa-Szczecin-Gdańsk: Fundacja Monumenta Archaeologica Barbarica, Muzeum Narodowe w Szczecinie, Fundacja Rozwoju Uniwersytetu Gdańskiego, Państwowe Muzeum Archeologiczne w Warszawie.

Madajski S. 1937. Cmentarzysko grobów skrzynkowych lub kloszowych i grobów z okresu późnolateńskiego we Włocławku. Z Otchłani Wieków 12, 76-79.

Malinowska H. 1967. Powiat rypiński w starożytności Skrwy. Toruń (unpublizierte Magisterarbeit im Archiv des Archäologisches Instituts, Nicolaus Copernicus Universität in Toruń).

Okuliczowie Ł. und J. 1976. Cmentarzysko kultury pomorskiej i z okresu rzymskiego w Michałkowie, pow. Dobrzyń, woj. Włocławek. Wiadomości Archeologiczne 41, 435-458.

Pietrzak M. 1997. Pruszcz Gdański Fundstelle 10. Ein Gräberfeld der Oksywie- und WielbarkKultur in Ostpommern (= Monumenta Archaeologica Barbarica 4). Kraków: Instytut Archeologii i Etnologii Polskiej Akademii Nauk, Muzeum Archeologiczne w Gdańsku. 
Piotrowski R. 1963. Sprawozdanie z przeprowadzonych badań powierzchniowych przez Ekspedycje UMK w Toruniu na terenie pow. Rypińskiego. Zbiór dokumentów Tysiąclecia Państwa Polskiego $w$ Rypinie 43. Rypin: Komisja obchodów Tysiąclecia Państwa Polskiego.

Romanowska-Grabowska O. 1972. Badania ratownicze na cmentarzysku z okresu rzymskiego w Ruży (Róży), w roku 1968 pow. Golub-Dobrzyń. In Komunikaty Archeologiczne. Badanie archeologiczne na terenie województwa bydgoskiego w latach 1968-1969, Bydgoszcz: Wojewódzki Konserwator Zabytków w Bydgoszczy, 55-61.

Romanowska-Grabowska O. und Janikowski J. 1982. Wyniki badań na cmentarzysku ciałopalnym z okresu wpływów rzymskich w Rużu, dawny powiat Golub-Dobrzyń. Rocznik Muzeum w Toruniu 8, 105-138.

Romanowski A. 2008. Die Fundmünzen der Römischen Zeit in Polen Rechtsufrigen Masowien und Podlachien (= Collection Moneta 84). Wetteren: Instytut Archeologii UW.

Romanowski A. 2011. Znaleziska Monet rzymskich na Ziemi Dobrzyńskiej. Rocznik Muzeum Ziemi Dobrzyńskiej w Rypinie 2, 39-47.

Schindler R. 1940. Die Besiedlungsgeschichte der Goten und Gepiden im unteren Weichselraum auf Grund der Tongefässe. Leipzig: C. Kabitzsch.

Schwandt W. 1905. Westpreussische Münzfunde. Beiträge zur Landeskunde Westpreussen. In Festschrift zum XV. deutschen Geographentag in Danzig überreicht vom Ortsausschuss, Danzig, 126-148.

Stawiarska T. 1999. Naczynia szklane z okresu rzymskiego z terenu Polski. Studium archeologiczno-technologiczne. Warszawa: Instytut Archeologii i Etologii PAN.

Sobczyk P. 2004. Penetracje terenowe Działu Archeologii MZKiD w latach 2001-2003. Rocznik Muzealny. Muzeum Ziemi Kujawskiej i Dobrzyńskiej we Włocławku 10, 5-34.

Sobczak P. 2008. Naukowo-Badawcza działalność archeologiczna Muzeum włocławskiego w latach 1957-2007. Rocznik Muzealny. Muzeum Ziemi Kujawskiej i Dobrzyńskiej we Włocławku 12, 201-207.

Tyszler L. 1999. Terra sigillata na ziemiach polskich (=Acta Archaeologica Lodziensia 43 und 44). Łódź: Łódzkie Towarzystwo Naukowe, Instytut Archeologii i Etnologii Polskiej Akademii Nauk.

Tyszler L. 2012. Ceramika rzymska na pótnoc od Karpat i Sudetów. Łódź: Instytut Archeologii Uniwersytetu łódzkiego.

Walenta K. 1977. Kręgi kamienne i kurhany w okresie wpływów rzymskich na Pomorzu. Archaeologia Baltica 2, 99-111.

Walenta K. 1981. Obrzq̨dek pogrzebowy na Pomorzu w okresie późnolatenskim i rzymskim (=Archaeologia Baltica 5). Łodź: Katedra Archeologii Uniwersytetu Łódzkiego.

Walenta K. 1992. Przyczynek do genezy wielbarskich cmentarzysk kurhanowych z kręgami kamiennymi. Archaeologica Lodziensia. Folia Archaeologia 16, 169-177.

Wołągiewicz R. 1977. Kręgi kamienne w Grzybnicy. Koszalin: Muzeum Okręgowe w Koszalinie.

Zieliński G. 1874. Starożytności Dobrzyńskie. Wiadomości Archeologiczne 2, 78-93.

Zieliński G. 1905. Monety rzymskie znalezione w naszych ziemiach. Wiadomości Numizmatyczno-Archeologiczne 5, 351-352.

Zielonka B. 1967. Kobryniec Nowy, pow. Rypin. Z Otchłani Wieków 33, 59. 
